\title{
Analisis Perubahan Suhu terhadap Panjang Gelombang pada Media Fiber Optik Berstruktur Singlemode-Multimode
}

\author{
Muhammad Adi Riswanto ${ }^{1}$, Mochammad Junus S.T, M.T. ${ }^{2}$, Drs. Yoyok Heru PI, M.T. ${ }^{3}$ \\ 1,2,3 Program Studi Jaringan Telekomunikasi Digital, \\ Jurusan Teknik Elektro, Politeknik Negeri Malang, Indonesia \\ 1'muhammad.adiris@gmail.com, ${ }^{2}$ mochammad.junus@polinema.ac.id, ${ }^{3}$ yoyok.heru@polinema.ac.id
}

\begin{abstract}
The increase in temperature on optical fiber results in an increase in the refractive index and Numerical Aperture, resulting in spread and absorption losses in the optical fiber. So it is considered necessary to discuss the effect of temperature changes on wave length in axially connected Singlemode-Multimode fiber optic media. Optical fiber connected to OSA is heated using a heater to show the wavelength value, before converted into color. Then convert it into CCT so as to produce a temperature value in kelvins. In this study, singlemode, multimode, singlemode-multimode fiber are used. The connection to each optical fiber and light source uses a Fusion Splicer and Visual Fault Locator with a wavelength of $660 \mathrm{~nm}$ and $680 \mathrm{~nm}$, respectively. Results show that the higher the temperature, the farther the wavelength shift. The singlemode-multimode cable has the farthest shift value of $8.44 \mathrm{~nm}$ at $660 \mathrm{~nm}$ and $9.3 \mathrm{~nm}$ at $680 \mathrm{~nm}$. Singlemodemultimode cable has the best measurement accuracy value. Because at a wavelength of $660 \mathrm{~nm}$, the difference between the temperature values measured on the thermocouple and those calculated on the matlab has an average percentage of 0.54\%. Meanwhile, at a wavelength of $680 \mathrm{~nm}$ it is $0.63 \%$.
\end{abstract}

Keywords-Temperature, Wavelength, Optical Fiber, Singlemode, Multimode, Singlemode-Multimode.

Abstrak - Kenaikan suhu pada fiber optik mengakibatkan kenaikan indeks bias dan Numerical Aperture, sehingga terjadinya rugi penyebaran dan penyerapan pada fiber optik. Maka dianggap perlu dilakukan penelitian yang membahas tentang pengaruh perubahan suhu terhadap panjang gelomboang pada media fiber optik berstruktur Singlemode-Multimode yang dihubungkan secara aksial. Fiber optik yang terhubung pada OSA dipanaskan mengunakan pemanas akan menunjukkan nilai panjang gelombang, nilai tersebut dikonversikan ke dalam warna. Kemudian mengkonversi ke dalam CCT sehingga menghasilkan nilai suhu dalam satuan kelvin. Pada penelitian ini menggunakan media fiber optik dengan struktur yang berbeda-beda yaitu singlemode, multimode, singlemodemultimode. Penyambungan pada tiap-tiap fiber optik menggunakan Fusion Splacer. Untuk sumber cahaya menggunakan Visual Fault Locator dengan panjang gelombang $660 \mathrm{~nm}$ dan $680 \mathrm{~nm}$. Berdasarkan hasil pengujian dapat disimpulkan bahwa semakin tinggi suhu yang diberikan, maka semakin jauh pergeseran panjang gelombang. Kabel singlemode-multimode memiliki nilai pergeseran paling jauh yaitu sebesar $8,44 \mathrm{~nm}$ pada panjang gelombang $660 \mathrm{~nm}$, serta sebesar $9,3 \mathrm{~nm}$ pada panjang gelombang $680 \mathrm{~nm}$. Kabel singlemodemultimode memiliki nilai akurasi pengukuran paling baik. Karena pada panjang gelombang $660 \mathrm{~nm}$, selisih antara nilai suhu yang terukur pada thermocouple dan yang terhitung pada matlab memiliki persentase rata-rata sebesar $0,54 \%$. Sementara pada panjang gelombang $680 \mathrm{~nm}$ sebesar $0,63 \%$.

Kata kunci-Suhu, Panjang Gelombang, Fiber Optik, Singlemode, Multimode, Singlemode-Multimode

\section{PENDAHULUAN}

Teknologi fiber optik sangat berkembang penggunaannya di Indonesia baik di bidang telekomunikasi, komputer, industri, peralatan kedokteran, maupun di bidang aplikasi militer dan masyarakat umum. Teknologi ini merupakan sistem jaringan komunikasi yang dalam pengiriman dan penerimaan sinyal informasinya yang berupa berkas cahaya, menggunakan sumber optik dan detektor optik, dengan fiber optik sebagai media transmisinya [1].

Salah satu permasalahan yang tidak dapat dihindari oleh fiber optik adalah karena letak geografis Indonesia yang berada di garis khatulistiwa mengakibatkan tingginya suhu rata rata tahunan[2]. Kenaikan suhu mengakibatkan kenaikan indeks bias dan Numerical Aperture, sehingga terjadinya rugi penyebaran dan penyerapan pada fiber optik[3].
Dengan adanya hal itu maka dianggap perlu dilakukan penelitian yang membahas tentang pengaruh perubahan suhu terhadap panjang gelomboang pada media fiber optik berstruktur Singlemode-Multimode yang dihubungkan secara aksial. Dipilihnya fiber optik berstruktur SinglemodeMultimode dikarenakan sensitif terhadap temperatur dan regangan, memiliki senstivitas yang tinggi, tidak membutuhkan waktu yang lama saat proses fabrikasi dan biaya yang relatif murah[4].

Pada penelitian sebelumnya telah dilakukan pengukuran suhu menggunakan media fiber optik berdasarkan nilai panjang gelombang[2]. Berdasarkan penelitian diatas maka pada penelitian ini akan dilakukan analisis perubahan suhu terhadap nilai panjang gelombang pada media fiber optik berstruktur singlemode-multimode yang bertujuan untuk mengetahui pengaruh perubahan suhu menggunakan OSA dan 
pemanas berdasarkan pendekatan matematis suhu dan panjang gelombang pada fiber optik.

Fiber optik merupakan sebuah bahan transparan yang sangat jernih atau kabel yang terbuat dari bahan semacam ini, yang dapat digunakan untuk mentransmisikan gelombang cahaya. Sistem fiber optik adalah sistem komunikasi data dan suara, atau cabang ilmu yang berurusan dengan sistem komunikasi, yang memanfaatkan fiber optik sebagai medium transmisinya. Fiber atau serat adalah sebutan singkat yang sering digunakan untuk kedua hal di atas di dalam berbagai situasi praktis. Maka, boleh juga dikatakan bahwa fiber digunakan pada sebuah sistem fiber[5]. Dua jenis fiber optik meliputi:

\section{a. Singlemode}

Fiber optik singlemode adalah sebuah sistem transmisi data berwujud cahaya yang didalamnya terdapat satu buah cahaya yang merambat di sepanjang fiber optik tanpa adanya pemantuluan[4].

\section{b. Multimode}

Fiber optik multimode merupakan teknologi transmisi data dengan memanfaatkan beberapa indeks cahaya yang terdapat di dalamnya. Fiber optik multimode dapat mentransmisikan cahaya dengan cara melakukan pemantulan berulang-ulang melalui permukaan cladding hingga sampai kearah panduan[4].

Gambar 1 menunjukkan diagram transmisi fiber optik. Informasi yang berupa suara, video dan data akan diubah oleh transducer menjadi sinyal informasi elektrik. Sinyal kan disesuaikan agar dapat dimodulasikan pada sumber optik pada saat data processing. Sumber optik mengubah sinyal elektrik menjadi sinyal informasi optik. Sejumlah daya diberikan oleh pengkopel kanal (masukan) ke media transmisi fiber optik agar sinyal informasi optik dapat diterima pada sisi penerima setelah melalui saluran fiber optik. Lalu sinyal informasi optik diubah kembali menjadi sinyal informasi elektrik. Dan setelah disesuaikan, sinyal informasi elektrik diubah menjadi informasi aslinya oleh suatu transducer[1].

\section{(Pengirim)}

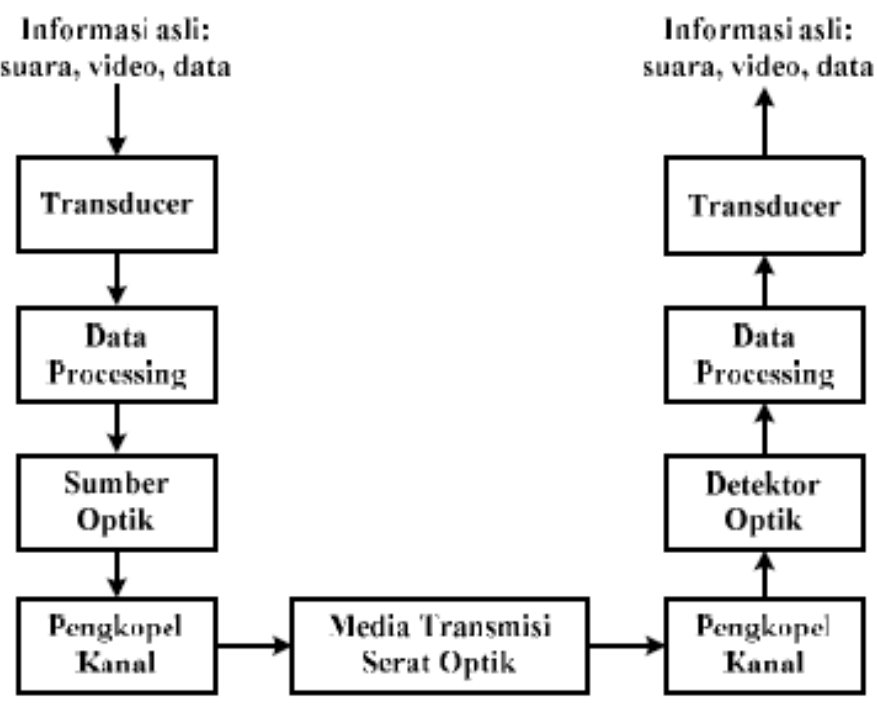

Gambar 1 Komunikasi Fiber Optik[1]

\section{METODE}

A. Penentuan Prosedur dan Parameter

Perancangan proses yang dikerjakan akan dijelaskan pada gambar 2

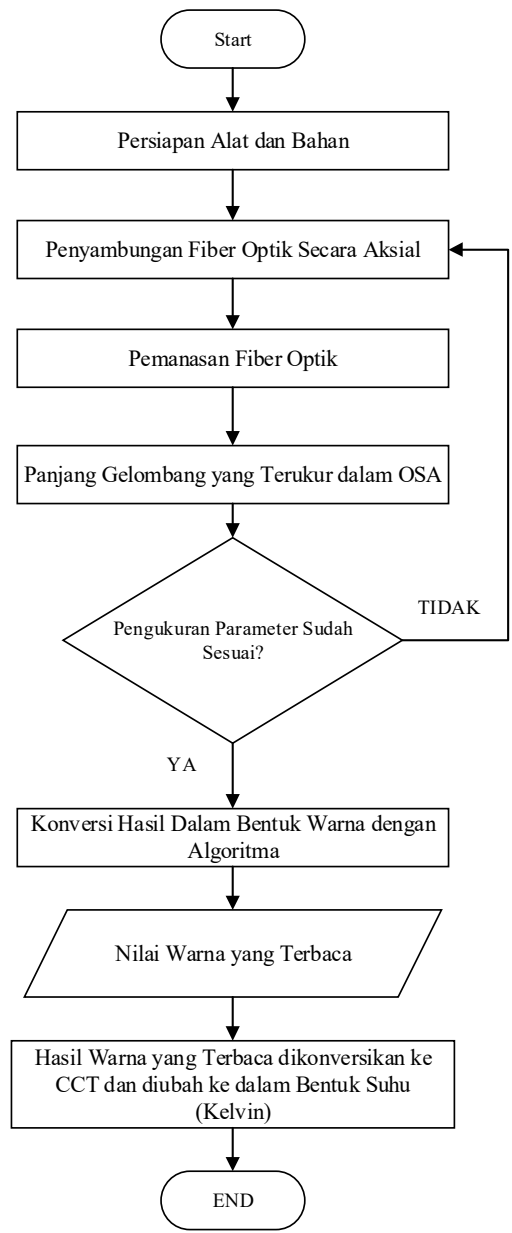

Gambar 2 Flowchart Sistem Pengkuran Suhu dan panjang gelombang

Pada diagram alir sistem penelitian diatas langkah pertama yang dilakukan adalah menyiapkan alat dan bahan yang akan digunakan. Langkah selanjutnya adalah melakukan pemanasan pada media fiber optik mengunakan pemanas. Fiber optik yang terhubung pada OSA akan menunjukkan nilai panjang gelombang dari fiber optik dan nilai panjang gelombang tersebut dapat dikonversikan ke dalam warna dengan menggunakan algoritma. Kemudian mengkonversi hasil perhitungan melalui algoritma ke dalam CCT sehingga menghasilkan nilai suhu dalam satuan kelvin. Pada penelitian ini menggunakan media fiber optik dengan struktur yang berbeda-beda yaitu singlemode, multimode, singlemodemultimode. Penyambungan pada tiap-tiap fiber optik dilakukan secara aksil dengan menggunakan Fusion Splacer. Untuk sumber cahaya yang ditransmisikan melalui fiber optik menggunakan Visual Fault Locator dengan panjang gelombang $660 \mathrm{~nm}$ dan $680 \mathrm{~nm}$.

Beberapa peralatan dan istilah yang digunakan meliputi:

1) Optical Spectrum Analyzer:

Sistem kerja dari Optical Spectrum Analyzer sendiri adalah ketika cahaya yang masuk melewati sebuah wavelength- 
tunable filter optik (monokromator atau interferometer). Photodetector kemudian mengkonversi sinyal optik menjadi arus listrik yang sebanding dengan daya optik. Arus dari photodetector diubah menjadi tegangan oleh penguat transimpedansi dan kemudian di digitalkan. Sinyal yang tersisa dari pengolahan, seperti menerapkan faktor pengoreksi, dilkukan secara digital. Sinyal kemudian diterapkan kedalam tampilan vertikal, atau amplitudo, data. Ramp generator menentukan lokasi horizontal dari trace saat sweep dari kiri ke kanan. Ramp juga menyetel filter optik sehingga panjang gelombang resonan proposional dengan posisi horizontal.

\section{2) Hotplate Magnetic Stirrer}

Prinsip kerja hotplate didasarkan pada proses perubahan energi listrik menjadi energi panas yang terjadi pada alas hotplate yang merupakan sebuah konduktor. Jadi, energi listrik yang berasal dari listrik yang mengalir ke hotplate, diubah menjadi energi panas pada alas/lempeng hotplate. Ini yang menyebabkan hotplate menjadi panas. Kemudia sebagian besar hotplate dilengkapi dengan magnetic stirrer. Fungsinya adalah untuk melakukan pengadukan dengan menggunakan stirrer magnet yang dicelup pada sampel.

\section{3) Thermocouple}

Prinsip kerja Termokopel cukup mudah dan sederhana. Pada dasarnya Termokopel hanya terdiri dari dua kawat logam konduktor yang berbeda jenis dan digabungkan ujungnya. Satu jenis logam konduktor yang terdapat pada Termokopel akan berfungsi sebagai referensi dengan suhu konstan (tetap) sedangkan yang satunya lagi sebagai logam konduktor yang mendeteksi suhu panas.

\section{4) Correlated Colour Temperature}

Nilai CCT dapat diperoleh dengan cara mencari nilai panjang gelombang melalui pengukuran, lalu nilai panjang gelombang tersebut diubah menjadi nilai RGB. Selanjutnya, merubah nilai RGB tersebut ke dalam nilai XYZ dengan menggunakan persamaan korelasi matriks transformasi 3 dimensi. Nilai XYZ tadi diubah dalam bentuk XY atau diproses menjadi transformasi 2 dimensi sesuai dengan persamaan yang ada. Setelah nilai XY didapatkan dengan menggunkan formula McCanny's maka akan didapatkan nilai CCT. Untuk mencari nilai CCT dapat ditemukan dengan menggunakan persamaan berikut[6]:

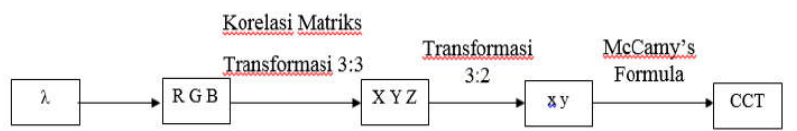

Gambar 3 diagram blok konversi panjang gelombang ke CCT

a. Konversi Panjang Gelombang ke RGB

Nilai panjang gelombang dapat di konversikan ke nilai RGB sebagai berikut :

$$
\begin{aligned}
& R=256 e-\left(\frac{\lambda-\frac{b+a}{2}}{\frac{b-a}{2}}\right)^{2} \\
& G=256 e-\left(\frac{\lambda-\frac{b+a}{2}}{\frac{b-a}{2}}\right)^{2}
\end{aligned}
$$

$$
B=256 e-\left(\frac{\lambda-\frac{b+a}{2}}{\frac{b+a}{2}}\right)^{2}
$$

\section{b. Konversi $R G B$ ke $X Y Z$}

$$
\begin{aligned}
& X=(-0.14282)(R)+(1.54924)(G)+(-0.95641)(B) . \\
& Y=(-0.32466)(R)+(1.57837)(G)+(-0.73191)(B) . \\
& Z=(-0.68202)(R)+(0.77073)(G)+(0.56332)(B) .
\end{aligned}
$$

c. Konversi XYZ ke xy

Setelah mendapatkan nilai XYZ yang merupakan bentuk 3 dimensi, kemudian di transformasi menjadi 2 dimensi dengan persamaan [7] berikut:

$$
\begin{aligned}
& \mathrm{X}=\frac{X}{X+Y+Z} . \\
& \mathrm{y}=\frac{Y}{X+Y+Z} .
\end{aligned}
$$

\section{d. Konversi xy ke CCT}

Sebelum masuk pada perhitungan CCT dicari terlebih dahulu nilai n dengan persamaan [7] berikut :

$$
n=\frac{x-0,3320}{0,1858-y}
$$

Setelah mendapatkan nilai xy kemudian dilakukan perhitungan ke CCT dengan persamaan[8] :

$$
C C T=449 n^{3}+3525 n^{2}+6823,3 n+624,13
$$

\section{5) Laser Optik}

Fiber Visual Fault Locator (VFL) adalah alat penting untuk setiap fiber tool kit Optik. Alat ini memungkinkan untuk dengan cepat mengidentifikasi kerusakan atau makro dalam serat optik, dan mengidentifikasi sambungan fusi yang buruk dalam multimode atau serat optik mode tunggal. VFL biasanya menggunakan sumber cahaya laser merah (635-690nm). Daya keluaran optik laser biasanya $1 \mathrm{~mW}$ atau kurang. Karena daya output optik yang tinggi, Anda tidak boleh melihat output VFL secara langsung. Visual Fault Locator tersedia dalam berbagai bentuk dan ukuran. Beberapa mungkin terlihat seperti pena, yang lain mungkin dibangun ke dalam optometer waktu domain optik (OTDR).

\section{B. Diagram Blok Pengukuran dan Perhitungan Pada Media Fiber Optik}

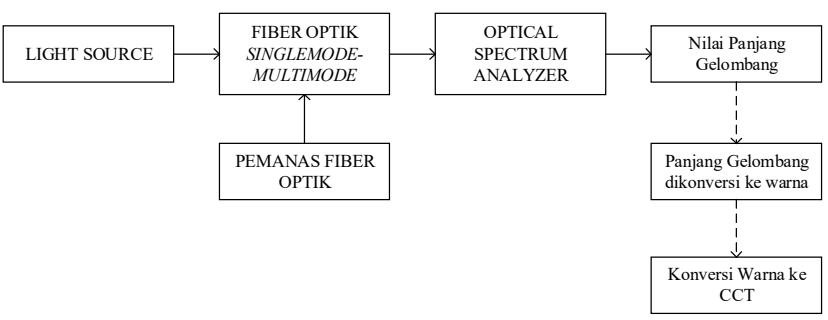

Gambar 4 Diagram Pengamatan Panjang Gelombang

Pada perencanaan alat uji pengukuran ini terdapat visual fault locator dengan panjang gelombang $660 \mathrm{~nm}$ dan $680 \mathrm{~nm}$ yang akan digunakan sebagai sumber cahaya. Dimana cahaya yang dihasilkan oleh laser akan ditrasmisikan melalui serat optic berstruktur singlemode, multimode, serta singlemode dan multimode yang disambungkan (singlemode-multimode) 
dengan menggunakan fusion splacer. Cahaya yang berada dalam fiber optik akan sulit keluar karena indeks bias dari kaca pada bahan fiber optic lebih besar dibandingkan indeks bias dari udara. Pada bagian tengah fiber optik dilakukan pengelupasan hingga menyisakan cladding, lalu dilakukan pemanasan menggunakan hotpate magnetic stirrer(pemanas) dengan bantuan plat alumunium yang di clamp pada bagian cladding. Lalu panas yang dihasilkan oleh pemans akan mempengaruhi cahaya yang ditransmisikan. Kemudian akan dilakukan pengukuran dimana pemanasan dimulai dari suhu ruang 30 dejarat celcius hingga 400 derajat celcius dengan interval 15 derajat celcius, dengan bantuan alat ukur berupa Optical Spectrum Analyzer yang akan mengukur nilai panjang gelombang. Nilai panjang gelombang akan dikonversi ke dalam nilai CCT.

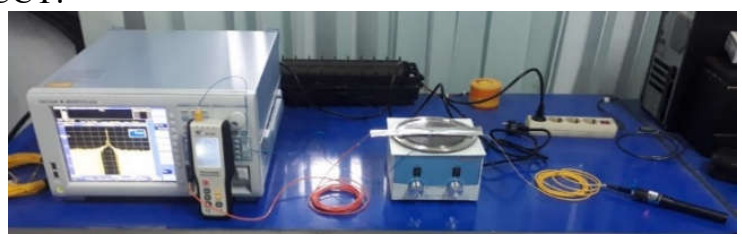

Gambar 5 Proses pengukuran pada singlemode-multimode

Pengambilan data menggunakan beberapa perangkat antara lain adalah Yokogawa AQ6370D Series Optical Spectrum Analyzer, Pemanas hotplate magnetic stirrer, Thermocouple Digital. Dan perangkat tambahan lainnya berupa kabel Singlemode, kabel multimode, Visual Fault Locator, Fiber Cleaver, Stripper, Fusion Splacer, konektor FC.

\section{HASIL DAN PEMBAHASAN}

A. Hasil pengukuran panjang gelombang pada kabel singlemode-multimode dengan sumber panjang gelombang $660 \mathrm{~nm}$

TABEL I

PENGUKURAN PANJANG GELOMBANG SINGLEMODE-MULTIMODE 660 NM

\begin{tabular}{cccc}
\hline No. & Suhu $(\mathbf{C})$ & $\boldsymbol{\lambda}(\mathbf{n m})$ & $\boldsymbol{\Delta} \boldsymbol{\lambda}(\mathbf{n m})$ \\
\hline 1 & 30 & 660,2 & 0 \\
\hline 2 & 45 & 660,51 & 0,31 \\
\hline 3 & 60 & 660,89 & 0,38 \\
\hline 4 & 75 & 661,21 & 0,32 \\
\hline 5 & 90 & 661,51 & 0,3 \\
\hline 6 & 105 & 661,93 & 0,42 \\
\hline 7 & 120 & 662,26 & 0,33 \\
\hline 8 & 135 & 662,58 & 0,32 \\
\hline 9 & 150 & 662,84 & 0,26 \\
\hline 10 & 165 & 663,21 & 0,37 \\
\hline 11 & 180 & 663,54 & 0,33 \\
\hline 12 & 195 & 663,87 & 0,33 \\
\hline 13 & 210 & 664,27 & 0,4 \\
\hline 14 & 225 & 664,55 & 0,28 \\
\hline 15 & 240 & 664,95 & 0,4 \\
\hline 16 & 255 & 665,27 & 0,32 \\
\hline 17 & 270 & 665,57 & 0,3 \\
\hline 18 & 285 & 665,96 & 0,39 \\
\hline 19 & 300 & 666,25 & 0,29 \\
\hline & & &
\end{tabular}

\begin{tabular}{cccc}
\hline No. & Suhu (C) & $\boldsymbol{\lambda}(\mathbf{n m})$ & $\boldsymbol{\Delta} \boldsymbol{\lambda}(\mathbf{n m})$ \\
\hline 20 & 315 & 666,59 & 0,34 \\
\hline 21 & 330 & 666,92 & 0,33 \\
\hline 22 & 345 & 667,27 & 0,35 \\
\hline 23 & 360 & 667,64 & 0,37 \\
\hline 24 & 375 & 667,98 & 0,34 \\
\hline 25 & 390 & 668,39 & 0,41 \\
\hline 26 & 400 & 668,62 & 0,23 \\
\hline$\Delta \lambda$ Rata-rata & & & 0,32
\end{tabular}

Pada tabel 1 nilai panjang gelombang awal sebelum kabel fiber optik dipanaskan sebesar $662,7 \mathrm{~nm}$. Pada saat suhu dinaikkan sebesar $15^{\circ} \mathrm{C}$ menjadi $45^{\circ} \mathrm{C}$ nilai panjang gelombang menjadi $663,03 \mathrm{~nm}$ atau bergeser $0,33 \mathrm{~nm}$. Nilai panjang gelombang menjadi $663,4 \mathrm{~nm}$ atau bergeser $0,37 \mathrm{~nm}$ ketika suhu kembali dinaikkan sebesar $15^{\circ} \mathrm{C}$ menjadi $60^{\circ} \mathrm{C}$. Dengan suhu yang terus dinaikkan dengan interval $15^{\circ} \mathrm{C}$, pada suhu $400^{\circ} \mathrm{C}$ nilai panjang gelombang sebesar $671,14 \mathrm{~nm}$. Nilai total pergeseran panjang gelombang pada kabel singlemodemultimode sebesar 8,44 $\mathrm{nm}$. sementara untuk nilai rata-rata pergeseran panjang gelombang ketika suhu dianaikkan tiap $15^{\circ} \mathrm{C}$ sebesar $0,32 \mathrm{~nm}$, yang dapat dihitung dengan persamaan[9] :

$$
\begin{aligned}
\Delta \lambda \text { Rata }- \text { rata } & =\frac{\Sigma \text { Pergeseran } \lambda}{\text { banyak data }} \\
& =\frac{8,44}{26} \\
& =0,32 \mathrm{~nm}
\end{aligned}
$$

$\rightarrow$ Singlemode $\quad \rightarrow-$ Multimode $\quad \rightarrow$ Singlemode-Multimode

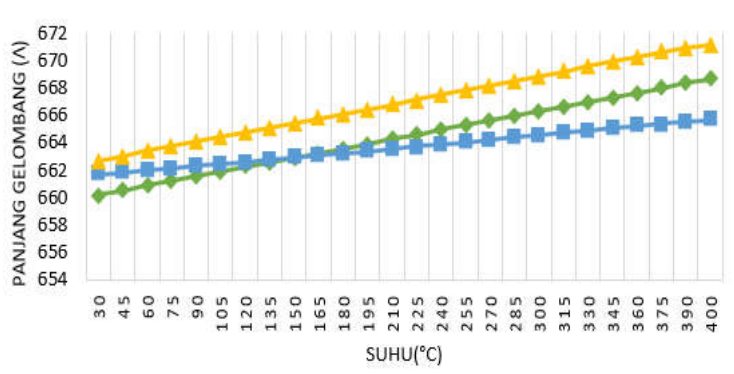

Gambar 6 Grafik Perbandingan Panjang Gelombang 3 kabel dengan sumber cahaya $660 \mathrm{~nm}$

B. Hasil pengukuran panjang gelombang pada kabel singlemode-multimode dengan sumber panjang gelombang $680 \mathrm{~nm}$

TABEL II PENGUKURAN PANJANG GELOMBANG SINGLEMODE-MULTIMODE 660

\begin{tabular}{cccc}
\hline \multicolumn{4}{c}{ NM } \\
\hline No. & Suhu $(\mathbf{C})$ & $\boldsymbol{\lambda}(\mathbf{n m})$ & $\Delta \boldsymbol{\lambda}(\mathbf{n m})$ \\
\hline 1 & 30 & 662,7 & 0 \\
\hline 2 & 45 & 663,03 & 0,33 \\
\hline 4 & 60 & 663,4 & 0,37 \\
\hline 5 & 75 & 663,75 & 0,35 \\
\hline 6 & 90 & 664,1 & 0,35 \\
\hline 7 & 105 & 664,38 & 0,28 \\
\hline
\end{tabular}


Jurnal Jaringan Telekomunikasi (Jurnal Jartel) E-ISSN:2654-6531 P-ISSN: 2407-0807 Vol. 10, No.3 (2020) 129-135

\begin{tabular}{cccc}
\hline No. & Suhu $(\mathbf{C})$ & $\boldsymbol{\lambda}(\mathbf{n m})$ & $\Delta \boldsymbol{\lambda}(\mathbf{n m})$ \\
\hline 8 & 135 & 665,04 & 0,28 \\
\hline 9 & 150 & 665,41 & 0,37 \\
\hline 10 & 165 & 665,78 & 0,37 \\
\hline 11 & 180 & 666,07 & 0,29 \\
\hline 12 & 195 & 666,42 & 0,35 \\
\hline 13 & 210 & 666,76 & 0,34 \\
\hline 14 & 225 & 667,11 & 0,35 \\
\hline 15 & 240 & 667,45 & 0,34 \\
\hline 16 & 255 & 667,83 & 0,38 \\
\hline 17 & 270 & 668,17 & 0,34 \\
\hline 18 & 285 & 668,49 & 0,32 \\
\hline 19 & 300 & 668,82 & 0,33 \\
\hline 20 & 315 & 669,19 & 0,37 \\
\hline 21 & 330 & 669,56 & 0,37 \\
\hline 22 & 345 & 669,9 & 0,34 \\
\hline 23 & 360 & 670,25 & 0,35 \\
\hline 24 & 375 & 670,62 & 0,37 \\
\hline 25 & 390 & 670,95 & 0,33 \\
\hline 26 & 400 & 671,14 & 0,19 \\
\hline & $\Delta \lambda$ Rata-rata & 0,32
\end{tabular}

Pada tabel 2 nilai panjang gelombang awal sebelum kabel fiber optik dipanaskan sebesar $683,6 \mathrm{~nm}$. Pada saat suhu dinaikkan sebesar $15^{\circ} \mathrm{C}$ menjadi $45^{\circ} \mathrm{C}$ nilai panjang gelombang menjadi $683,95 \mathrm{~nm}$ atau bergeser $0,35 \mathrm{~nm}$. Nilai panjang gelombang menjadi $684,34 \mathrm{~nm}$ atau bergeser $0,39 \mathrm{~nm}$ ketika suhu kembali dinaikkan sebesar $15^{\circ} \mathrm{C}$ menjadi $60^{\circ} \mathrm{C}$. Dengan suhu yang terus dinaikkan dengan interval $15^{\circ} \mathrm{C}$, pada suhu $400^{\circ} \mathrm{C}$ nilai panjang gelombang sebesar $692,9 \mathrm{~nm}$. Nilai total pergeseran panjang gelombang pada kabel singlemodemultimode sebesar 9,3 $\mathrm{nm}$. Sementara untuk nilai rata-rata pergeseran panjang gelombang ketika suhu dianaikkan tiap $15^{\circ} \mathrm{C}$ sebesar $0,36 \mathrm{~nm}$, yang dapat dihitung dengan menggunakan persamaan berikut[9] :

$$
\begin{aligned}
\Delta \lambda \text { Rata }- \text { rata } & =\frac{\Sigma \text { Pergeseran } \lambda}{\text { banyak data }} \\
& =\frac{9,3}{26} \\
& =0,36 \mathrm{~nm}
\end{aligned}
$$

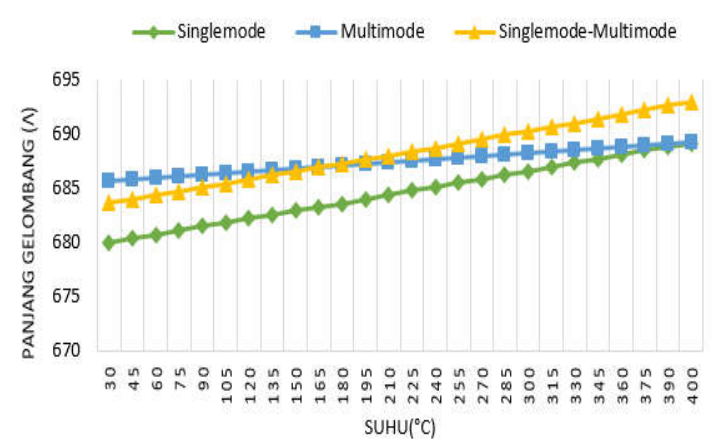

Gambar 7 Grafik Perbandingan Panjang Gelombang 3 kabel dengan sumber cahaya $680 \mathrm{~nm}$

C. Konversi ke CCT kabel Singlemode-Multimode 660 $n m$

TABEL III

KONVERSI KE CCT SINGLEMODE-MULTIMODE $660 \mathrm{NM}$

\begin{tabular}{cccc}
\hline No. & Suhu Terukur (C) & CCT Terhitung (C) & \%Error \\
\hline 1 & 30 & 30,023 & 0,08 \\
\hline 2 & 45 & 44,574 & 0,95 \\
\hline 3 & 60 & 60,903 & 1,51 \\
\hline 4 & 75 & 76,361 & 1,81 \\
\hline 5 & 90 & 91,826 & 2,03 \\
\hline 6 & 105 & 104,2 & 0,76 \\
\hline 7 & 120 & 120,99 & 0,82 \\
\hline 8 & 135 & 133,36 & 1,21 \\
\hline 9 & 150 & 149,7 & 0,2 \\
\hline 10 & 165 & 166,03 & 0,62 \\
\hline 11 & 180 & 178,81 & 0,66 \\
\hline 12 & 195 & 194,22 & 0,4 \\
\hline 13 & 210 & 209,17 & 0,4 \\
\hline 14 & 225 & 224,52 & 0,21 \\
\hline 15 & 240 & 239,39 & 0,25 \\
\hline 16 & 255 & 255,98 & 0,38 \\
\hline 17 & 270 & 269,89 & 0,04 \\
\hline 18 & 285 & 284,63 & 0,13 \\
\hline 19 & 300 & 298,88 & 0,37 \\
\hline 20 & 315 & 314,79 & 0,07 \\
\hline 21 & 330 & 330,61 & 0,18 \\
\hline 22 & 345 & 345,07 & 0,02 \\
\hline 23 & 360 & 359,86 & 0,04 \\
\hline 24 & 375 & 375,4 & 0,11 \\
\hline 25 & 390 & 389,15 & 0,22 \\
\hline 26 & 400 & 397,02 & 0,75 \\
\hline & & & 0,54 \\
\hline & & & \\
\hline & & & \\
\hline
\end{tabular}

Pada kabel singlemode-multimode $660 \mathrm{~nm}$ dipanaskan dengan suhu $60^{\circ} \mathrm{C}$ didapatkan nilai panjang gelombang 663,4 $\mathrm{nm}$. Nilai panjang gelombang yang terukur dapat dikonversikan menggunakan CCT untuk mendapatkan nilai suhu yang terhitung, pehitungan CCT dapat menggunakan persamaan berikut :

\section{1) Konversi Panjang Gelombang ke RGB}

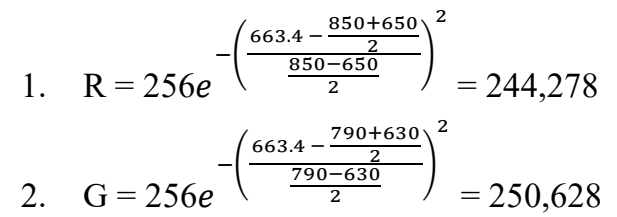

$\mathrm{B}=256 e^{-\left(\frac{663.4-\frac{620+500}{2}}{\frac{620-500}{2}}\right)^{2}}=212,631$

2) Konversi $R G B$ ke $X Y Z$

$\mathrm{X}=(-0.14282)(244,278)+(1.54924)(250,628)+(-0.95641)(212,631)$

$=150,033$

$\mathrm{Y}=(-0.32466)(244,278)+(1.57837)(250,628)+(-0.73191)(212,631)$

$=160,65$

$Z=(-0.84379)(244,278)+(0.75797)(250,628)+(4.99472)(212,631)$

$=1045,88$ 
Jurnal Jaringan Telekomunikasi (Jurnal Jartel) E-ISSN:2654-6531 P-ISSN: 2407-0807 Vol. 10, No.3 (2020) 129-135

3) Konversi xy ke CCT

$$
\begin{aligned}
& x=\frac{150,33}{(150,33+160,65+1045,88)}=0,1106 \\
& y=\frac{160,65}{(150,33+160,65+1045,88)}=0,1184
\end{aligned}
$$

4) Konversi $x y$ ke CCT

$$
\begin{gathered}
n=\frac{(0,1106-0,3320)}{(0,1858-0,1184)}=-3,286 \\
\text { CCT }=449(-3,286)^{3}+3525(-3,286)^{2}+ \\
6823,3(-3,286)+624.13=333,903^{\circ} \mathrm{K} \\
\text { celcius }=333,903-273 \\
\text { CCT }=60,903^{\circ} \mathrm{C}
\end{gathered}
$$

5) Nilai Error antara pengukuran dan perhitungan

Untuk mengetahui nilai error antara nilai pengukuran dengan nilai perhitungan menggunakan matlab, maka nilai error dapat dicari dengan cara [10] :

$$
\% \text { Error }=\frac{|60-60,903|}{60} \times 100=1,51 \%
$$

D. Konversi ke CCT kabel Singlemode-Multimode 680 $n m$

TABEL IV

KONVERSI KE CCT SINGLEMODE-MULTIMODE $680 \mathrm{NM}$

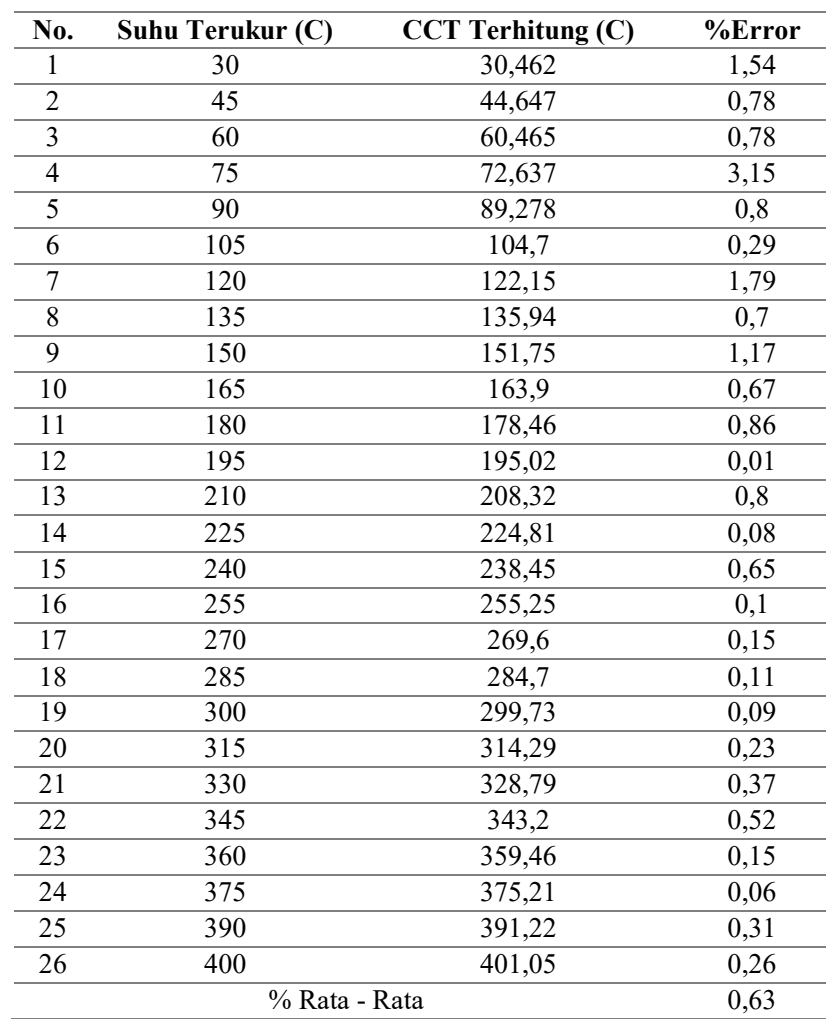

Pada kabel singlemode-multimode $680 \mathrm{~nm}$ dipanaskan dengan suhu $60^{\circ} \mathrm{C}$ didapatkan nilai panjang gelombang 684,34 $\mathrm{nm}$. Nilai panjang gelombang yang terukur dapat dikonversikan menggunakan CCT untuk mendapatkan nilai suhu yang terhitung, pehitungan CCT dapat menggunakan persamaan berikut :

\section{1) Konversi Panjang Gelombang ke RGB}

3. $\mathrm{R}=256 e^{-\left(\frac{684,34-\frac{850+650}{2}}{\frac{850-650}{2}}\right)^{2}}=249,19$

4. $\mathrm{G}=256 e^{-\left(\frac{684,34-\frac{790+630}{2}}{\frac{790-630}{2}}\right)^{2}}=254,36$

$\mathrm{B}=256 e^{-\left(\frac{684,34-\frac{620+500}{2}}{\frac{620-500}{2}}\right)^{2}}=195,736$

2) Konversi $R G B$ ke $X Y Z$

$\mathrm{X}=(-0.14282)(249,19)+(1.54924)(254,36)+(-0.95641)(195,736)$

$=171,27$

$\mathrm{Y}=(-0.32466)(249,19)+(1.57837)(254,36)+(-0.73191)(195,736)$

$=177,31$

$Z=(-0.84379)(249,19)+(1.41915)(254,36)+(4.99472)(195,736)$

$=1128,35$

3) Konversi XYZ ke $x y$

$$
\begin{aligned}
& x=\frac{171,27}{(171,27+177,31+1128,35)}=0,11596 \\
& y=\frac{177,31}{(171,27+177,31+1128,35)}=0,12005
\end{aligned}
$$

4) Konversixy ke CCT

$$
\begin{gathered}
n=\frac{(0,11596-0,3320)}{(0,1858-0,12005)}=-3,286 \\
\text { CCT }=449(-3,286)^{3}+3525(-3,286)^{2}+ \\
6823,3(-3,286)+624.13=333,465^{\circ} \mathrm{K} \\
\text { celcius }=333,465-273 \\
=60,465^{\circ} \mathrm{C}
\end{gathered}
$$

\section{5) Konversi xy ke CCT}

Untuk mengetahui nilai error antara nilai pengukuran dengan nilai perhitungan menggunakan matlab, maka nilai error dapat dicari dengan cara [10]:

$$
\% \text { Error }=\frac{|60-60,465|}{60} \times 100=0,78 \%
$$

\section{KESIMPULAN}

Variasi suhu yang diberikan menghasilkan kesimpulan bahwa semakin tinggi suhu yang diberikan, maka semakin jauh pergeseran panjang gelombang. Kabel singlemode-multimode memiliki nilai pergeseran paling jauh di antara 3 jenis struktur kabel lain. Pada sumber panjang gelombang $660 \mathrm{~nm}$, nilai pergeseran panjang gelombang sebesar $8,44 \mathrm{~nm}$ dengan nilai pergeseran rata-rata tiap $15^{\circ} \mathrm{C}$ sebesar $0,32 \mathrm{~nm}$. Pada sumber panjang gelombang $680 \mathrm{~nm}$, nilai pergeseran panjang gelombang sebesar $9,3 \mathrm{~nm}$ dengan nilai pergeseran rata-rata tiap $15^{\circ} \mathrm{C}$ sebesar $0,36 \mathrm{~nm}$.

Kabel singlemode-multimode memiliki nilai akurasi pengukuran paling baik. Karena pada panjang gelombang 660 
$\mathrm{nm}$, selisih antara nilai suhu yang terukur pada thermocouple dan yang terhitung pada matlab memiliki persentase rata-rata sebesar $0,54 \%$. Sementara pada panjang gelombang $680 \mathrm{~nm}$ sebesar $0,63 \%$.

\section{REFERENSI}

[1] A. Hanafiah R, “Teknologi Serat Optik,” J. Sist. Tek. Ind., vol. 7, no. 1, pp. 87-91, 2006.

[2] A. G. Gumilang, Y. H. P. Isnomo, and Waluyo, "pengukuran suhu menggunakan media fiber optik berdasarkan nilai panjang gelombang," pp. 1-10, 2019.

[3] N. H. Kunlavia, S. H. Pramono, and S. N. Sari, "Pengaruh temperatur terhadap kinerja plastic optical fiber (pof) jenis step index multimode pada sistem komunikasi serat optik," 2005.

[4] A. Rino, "Kajian Eksperimental Sensor Pergeseran Rentang Panjang Menggunakan Serat Optik Berstruktur Singlemode Singlemode ( SMS )," 2014.

[5] H. P. Utoyo, "Uji Sensitivitas Sensor Suhu Berbasis Fiber Optik Polymer ( Pof ) Yang Berbentuk Spiral Dan Berjaket Gel," 2017.

[6] Y. H. P. Isnomo, M. N. Zakaria, M. Junus, M. A. Anshori, and A. Aisah, "Optical fiber temperature sensor design," IOP Conf. Ser. Mater. Sci. Eng., vol. 732, no. 1, 2020.

[7] Joe Smith, Calculating Color Temperature and Illuminance using the TAO TCS3414CS Digital Color Sensor, vol. 43, no. figure 1. 2009.

[8] C. Tatu, "Correlated color temperature determination for led modulesusing a digital color sensor," UPB Sci. Bull. Ser. A Appl. Math. Phys., vol. 75, no. 1, pp. 225-232, 2013.

[9] Sugiyono, "Statistik Untuk Penelitian.pdf." pp. 1-370, 2007.

[10] Harinaldi, Prinsip-prinsip Statistik untuk Teknik dan Sains. Erlangga, 2005. 